\title{
DESIGN BY TESTING OF INDUSTRIAL RACKS
}

\author{
N. Baldassino and R. Zandonini * \\ Department of Mechanical and Structural Engineering, University of Trento, \\ 38123 Povo, Trento, Italy \\ *(Corresponding author: E-mail: Riccardo.Zandonini@ing.unitn.it)
}

\begin{abstract}
Industrial racks are one of the most common structures for the storage of palletised goods. The behaviour of these structures, which are built-up from thin-walled cold-formed steel profiles, is quite complex. The sensitivity of the uprights to buckling, the presence of the perforations on the uprights, the non linearity of the connections, the frame sensitivity to the second-order effects and the influence of the imperfections are the main sources of complexity. The large variability in terms of geometry of the profiles, of the joints and of the perforations, and the complexity of the phenomena which affects the member behaviour do not yet allow performing a pure numerical design, but call for tests aimed at the characterisation of the structural components. Traditionally, the design of the racks is carried out by a procedure combining experiments and numerical analysis. This approach follows the so-called 'design by testing'. This paper intends to provide an overview of the experimental part of the approach. The specifications in the European and the North American standards are reviewed for the main structural components, i.e., the uprights, the upright frames and the joints. Problems related to the clarity, accuracy and completeness of the specifications are pointed out. The main results of some studies carried out by the authors provide a key to better understanding of the importance of testing.
\end{abstract}

Keywords: Industrial racks, design by testing, experimental analysis, numerical analysis, member buckling, semi-rigid joints

\section{INTRODUCTION}

In modern steel construction thin walled cold-formed profiles are becoming increasingly popular. The particular manufacturing processes [1] adopted for these profiles, which consist of rolling, pressing or bending brake of thin coils, lead to a great flexibility of the section shapes and to a significant weight reduction [2]. In recent years, the improvements of manufacturing techniques, the adoption of corrosion protection, the application of techniques of shape optimization and the increased structural performance have led to a wider use of cold-formed profiles. Roof and wall systems, trusses, wall framing, steel decking for composite structures, and industrial rack structures are some typical applications [2]. The design of each category of light gauge structures requires that some peculiar problems are mastered.

This paper focuses on the design of rack structures and, in particular, of pallet rack systems. These structures are one of the most common industrial storage systems for palletised goods. These systems are laid down along the aisles used to move the pallets. They are built up as a series of braced upright frames in the cross-aisle direction, connected in the transverse direction (the down-aisle direction) by beam elements (Figure 1). The efficiency of storage depends on the capability of the rack system to adapt to the type and geometry of the pallets. This goal is achieved mainly via a flexible geometry in terms of distance between upright frames and free height available between beam levels. 

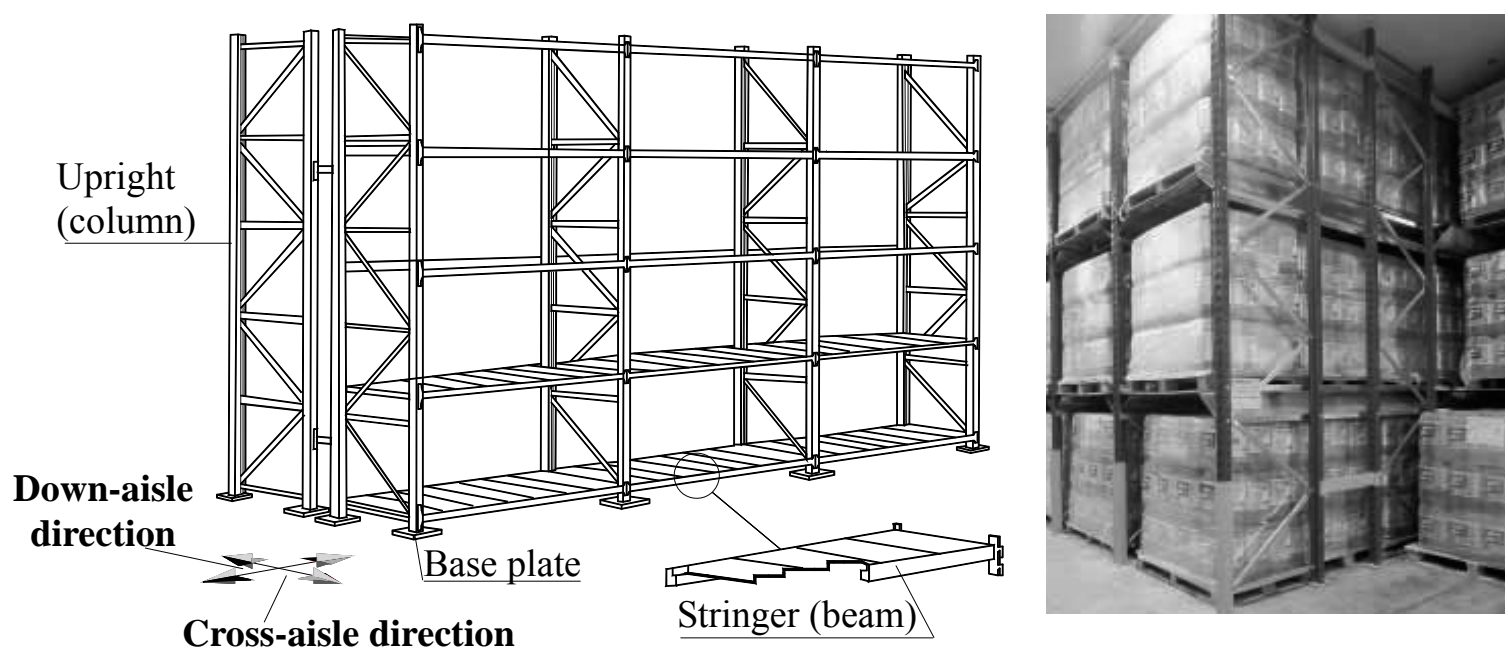

Figure 1. A Typical Steel Storage Pallet Rack System

The uprights are open thin-walled members. Their section shape is a ' $\mathrm{C}$ like' section stiffened by lips and, in some cases, by rear flanges and additional lips. The uprights usually contain holes and/or perforations at regular spacing to allow for the beam and the bracing connections. Beams, which usually have boxed cross sections, are provided by end-plates to allow for a mechanical connection to the uprights. The connection to the pavement is built-up by means of base plates, which can be either bolted or welded to the upright, and anchored to the floor. The bracings in the cross-aisle direction are usually made of open or closed cross section profiles eccentrically bolted to the uprights. In the down-aisle direction, racks are often unbraced frames: the need of efficiently storing and handling the pallets prevents the location of bracing systems in this plane. Therefore, the frame lateral stability in the down-aisle direction is generally provided by the degree of continuity offered by the beam-to-column and by the base-plate joints.

From the structural point of view racks can be considered as framed steel structures, characterised by a great sensitivity to second-order effects. For the purpose of global analysis, second-order analysis of the whole system (3-D analysis) or of the sub-frames in the planes parallel and perpendicular to the aisles (2-D analysis) may be performed. In the latter case, a semi-continuous frame model has to be considered in the down-aisle direction. The design of these structures is quite complex. The system members are prone to different forms of buckling, as all the thin walled members, while the perforation of the uprights adds further complexity to the instability phenomena. Moreover, both beam-to-column and base-plate joints are partial strength joints and exhibit a highly nonlinear response. Therefore, the analysis is fairly sophisticated and difficult to be mastered by numerical methods only. This is reflected in the design philosophy adopted by the main Standards for the design of pallet racks [3,4,5]. All Standards adopt a 'design by testing' approach which combines the results of experiments on components and sub-frames with the theoretical criteria developed and codified for traditional cold-formed members. Suitable tests are specified to define the main behavioural parameters of the key components or the sub-assemblages.

This paper intends to provide a concise overview of the experimental approach adopted by the European and the North American Standards for industrial racks [3,5]. The overview focuses on the key rack structural elements, i.e., the uprights, the upright frames and the beam-to-column and base joints. Problems related to the clarity, accuracy and completeness of the specifications are pointed out. Grounds for improving the Standards are identified. Furthermore, the main results of some studies carried out by the authors provide a better understanding of the importance of testing. 


\section{UPRIGHTS}

The columns of the pallet racks are mostly cold-formed open thin-walled steel sections. Their shape depends on the type of connection with the bracing members (cross-aisle direction) and with the beams (down-aisle direction). Complexity is also due to the constant process of innovation associated with competitive design. Moreover, in order to facilitate flexibility in the location of the connections, the upright is perforated along its length. Shape and distribution of perforations add complexity to the problem of defining the response of the upright itself. The behaviour of the uprights is in fact significantly affected by different forms of buckling. In addition to local and global buckling phenomena, distortional buckling should be considered. Interaction between the different buckling modes may also occur.

Since the 60's, several studies were carried out aimed at investigating the behaviour of upright sections. The research work focused on different issues, such as the possible buckling modes $[6,7,8]$ and their interaction $[9,10]$, the influence of the residual stresses $[11,12]$, and the influence of the perforation [13]. These studies combined experimental and numerical analyses.

The complexity of the phenomena characterising the upright response and the wide range of cross sectional shapes make it difficult to identify general solutions to the problem. The main Standards for the design of thin walled structures provide simplified equations which allow tackling the most common design cases. The effective width approach is adopted to account for local buckling; more complex, but conservative, equations are also proposed for checking distortional buckling, while separate formulas are given for verifying the overall instability.

For the more complex upright sections, the European and the North American Standards prescribe rational analysis or an experimental approach. The finite element method [14], the finite strip method [15], the generalised beam theory $[16,17,18]$ or the direct strength method [10] can be adopted as effective and rational tools of analysis.

The influence of the perforations is taken into account by the Standards only by modifying the effective area. Weakening of the resistant section, localised alteration of the material properties and stress concentrations due to the discontinuity are the principal consequences of perforations. The variety of the geometry and shape of both the perforations, the upright cross sections and the interval between perforations make each case unique and do not enable identification of general equations. Various numerical and experimental studies about the effects of perforations on the failure mode and collapse load were recently carried out [19-22]. Simplified relationships were also established, which do have the strong limitation that they are related to particular perforation geometries and sections. Therefore, the most appropriate solution to analyse the behaviour of the perforated sections seems to be the experimental approach, already specified by the European and the North American Standards [3,5] for perforated members. In particular, the European Standard [3] prescribes how to investigate the upright behaviour under compression and under bending, with the aim to assess the effective properties of the section. In the following, the case of an upright in compression is used for illustrative purposes.

The European Standard [3] specifies different compression tests aimed at investigating the sensitivity of the upright to local and distortional buckling. A minimum number of three tests is specified, in order to enable statistical evaluation of the parameters under consideration. The stub-column test, i.e., a compression test on a short specimen, is adopted for singling out the effect of local buckling. The length of the specimen should to be selected so that, on the one hand, local buckling is the sole buckling mode present and, on the other hand, there exists a uniformly compressed central zone. A further requirement of including at least 5 pitches of perforations is 
given. The ends of the specimen are welded to steel plates which allow the connection to the test rig (Figure 2). The end fixtures should provide hinged restraints.

A key point in compression tests is the selection of the point of application of the load. Since the section properties change along the upright due to the presence of the perforations, it is not possible to identify a centroidal axis of the member. In other words, concentrically loaded specimens do not exist. The problem is further complicated when local buckling takes place, inducing additional changes of the effective cross section.
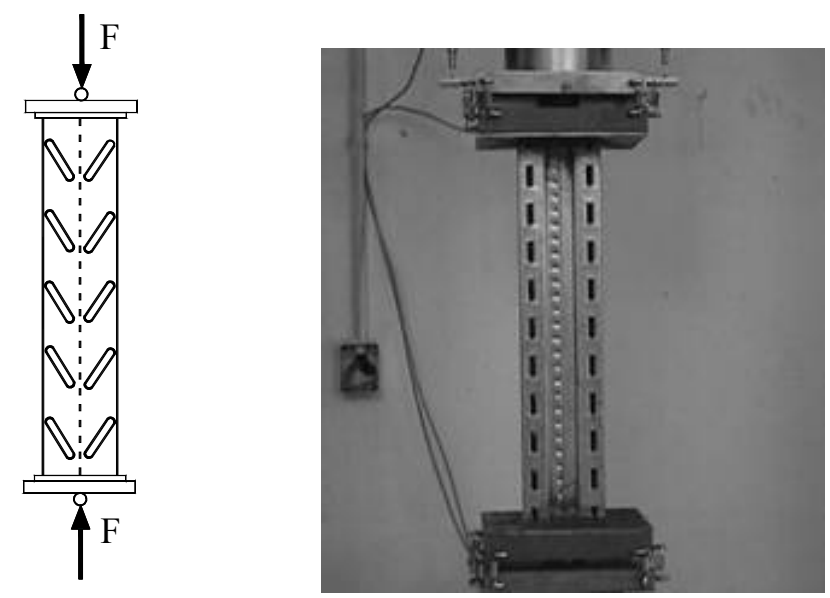

Figure 2. Stub-column Test Set-up

Baldassino and Hancock [23] studied the influence of the load eccentricities on the upright response under compression. They analysed a particular section profile and compared the experimental results of specimens with and without perforations. The non negligible influence of the load eccentricity on both the collapse load and failure mode was unveiled. Such an influence is strongly dependent on the length of the specimen. No general rule can be given for the load eccentricity. Therefore, the European Standard [3] recommends applying the load in the location between the centroids of the gross and net areas that provides the 'maximum failure load'. In order to satisfy this condition, a series of preliminary tests is required.

The final purpose of the stub-column tests is the assessment of the upright effective area ( $\mathrm{A}_{\text {eff }}$ ), which is determined as:

$$
A_{\text {eff }}=\frac{R_{k}}{f_{y}}
$$

where $R_{k}$ is the characteristic value of the collapse load and $f_{y}$ is the yield stress of the steel.

The effective area $\mathrm{A}_{\text {eff }}$ takes into account, in a simplified way, the effect of local buckling, the perforations and the cold-work process.

The North American Standard [5] prescribes a similar approach. The main difference is the end restraint conditions, which are fixed instead of hinged. The tests allow the definition of a reduction factor $\mathrm{Q}$, obtained as the ratio between the collapse load and the maximum resistance of the minimum net section $\left(f_{y} * A_{n e t, m i n}\right)$. In design, this $Q$-factor enables the determination of the effective properties of the cross-section. 
The particular shape of the upright, with additional lips or rear flanges and additional lips, certainly improves the performance of the section against overall buckling, but increases its sensitivity to distortional buckling. Occurrence of distortional buckling generally triggers rapid failure: the associated in-plane deformation can induce remarkable membrane stresses which can lead to the yielding with subsequent failure of the stiffeners.

In order to investigate this feature, both the European and the North American Standards [3,5] specify the use of numerical or experimental approaches. Furthermore, the European Standard [3] provides a procedure that combines theoretical and experimental analysis and appears the most suitable for perforated members.

The European Standard [3] specifies two experimental approaches involving a quite different amounts of work. In both cases the tests are aimed at investigating the sensitivity of the upright to distortional buckling in the down-aisle direction. The test should be performed considering, as much as possible, the actual restraint conditions provided by the bracing system in the cross-aisle direction and by the beams in the down-aisle direction. In racks, the peculiar type of beam-to-column joints and the regularity of the perforation on the upright allow modifying the beam levels during the structural life of the storehouse. The uncertainty in the beam positions suggests disregarding, in the tests, the restraint offered by the beams. Both proposed experimental approaches adopt this simplification.

The 'simpler' approach consists of a compression test of an upright specimen of length equal to that of the single bracing panel closest to one meter. The provision 'closest to one meter' is of unclear origin and seems not reasonable in the case of bracing panel lengths different from one meter. Moreover, it seems to contradict a prescription of the same Standard which states that all bracing lengths should be experimentally or numerically investigated. The specimen set-up and the test procedure are the same as those prescribed for the stub-column test. Preliminary trial tests must be carried out to select the point of application of the axial force. When distortional buckling governs, its effect is accounted for by a suitable re-definition of the effective cross sectional area.

The second approach for the distortional check consists of the determination of the upright buckling curve. The compression tests are performed so that a representative range of upright frame lengths is covered. Two alternative test set-ups can be adopted, as shown in Figure 3. The failure load data associated to the tested bracing lengths are evaluated following the prescription of the European Standard [3]. The final goal of the test procedure is to plot a curve providing the variation of a stress reduction factor $\left(\chi_{\mathrm{ni}}\right)$ with the non-dimensional slenderness $\left(\bar{\lambda}_{\mathrm{ni}}\right)$.

Concerning global buckling, no specific test procedure is prescribed by the Standards. The buckling theory of thin walled members is adopted to define the curves for flexural or flexural-torsional buckling. It is implicit that perforations do have a limited influence on the overall upright response.

This brief summary clearly points out the complexity of the procedure adopted by the Standards. With the exception of the simpler upright geometries (simple section shapes and/or no perforations), a significant effort is required on both the experimental and the numerical sides. Tests certainly allow investigating the more complex problems but a strong limitation is the difficulty in reproducing the actual restraint conditions. The number of tests is further increased by the need for a statistical assessment. If the same upright section is used in different panel lengths or with different wall thickness, the experimental effort increases proportionally. Although the numerical approach makes it possible to reduce the number of tests, it must be viewed as a complementary tool: due to the presence of the perforations, quite complex models are required which, in any case, must be calibrated against experimental results. 

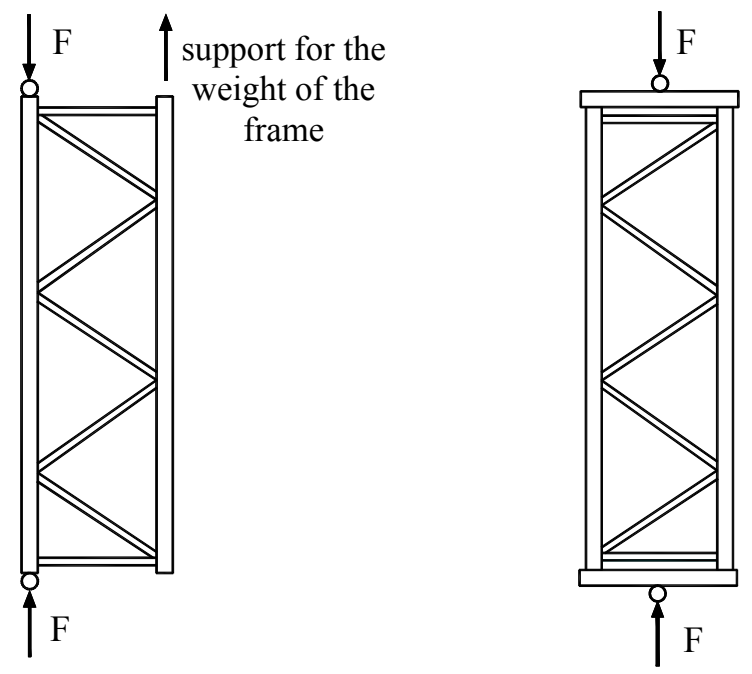

Figure 3. Test Set-ups for the Evaluation of the Buckling Curve

\section{UPRIGHT FRAMES}

The stability of rack systems in the cross-aisle direction is provided by the bracing system which connects the uprights. In this plane, the rack is hence comparable to a latticed column. The particular features of these systems, which are characterised by uprights with open cross section, by bracing members eccentrically connected to the uprights and, in the case of bolted connection, by a non-negligible lack of fits, make them particularly sensitive to second-order effects. This aspect stresses the need of an accurate evaluation of their deformability and of the selection of the most appropriate method of analysis.

In lattice structures the evaluation of the elastic critical load $V_{c r}$ requires taking into account both the flexural deformability and the shear deformability. For these systems, $\mathrm{V}_{\mathrm{cr}}$ is given by:

$$
\mathrm{V}_{\mathrm{cr}}=\frac{1}{\frac{1}{\mathrm{~V}_{\mathrm{cr}}^{*}}+\frac{1}{\mathrm{~S}_{\mathrm{D}}}}
$$

where $\mathrm{V}^{*}$ cr is the elastic critical load disregarding the shear deformability of the bracing system and $\mathrm{S}_{\mathrm{D}}$ is the shear stiffness per unit length of the bracing system, both of which can be determined theoretically. Both the European and the North American Standards provide specific equations for the most common types of bracing systems [3,5]. These equations are based on the assumption of elastic behaviour of 'ideal' upright frame systems [6]. Factors such as the axial shortening of the uprights, the eccentricities of the bracing, the connections lack of fit and the structural imperfections are neglected. To analyse the influence of such factors, the European Standard [3] recommends the experimental approach as an alternative to the theoretically evaluation. With this aim a testing procedure is specified. A shear force $(\mathrm{F})$ is applied to an upright frame segment composed by at least two complete bracing panels (Figure 4). The purpose of the test is to determine the 'initial' frame elastic shear stiffness. A value of $\mathrm{F}$ equal to $2 * \mathrm{n} \mathrm{kN}$ is indicated, where $\mathrm{n}$ is the number of bracing panels of the specimen. The displacement of the loaded upright is measured and the load-displacement curve ( $F-\delta$ curve) enables the evaluation of the shear stiffness $\mathrm{S}_{\mathrm{D}}$ as: 
$\mathrm{S}_{\mathrm{D}}=\frac{\mathrm{k}_{\mathrm{ti}} \mathrm{d}^{2}}{\mathrm{~h}}$

where $\mathrm{k}_{\mathrm{ti}}$ is the slope of the best-fit straight line of the experimental curve (F- $\delta$ curve), $\mathrm{d}$ is the distance between the centroidal axes of the uprights (Figure 5) and $\mathrm{h}$ is the distance between the restraints on the uprights (Figure 5).
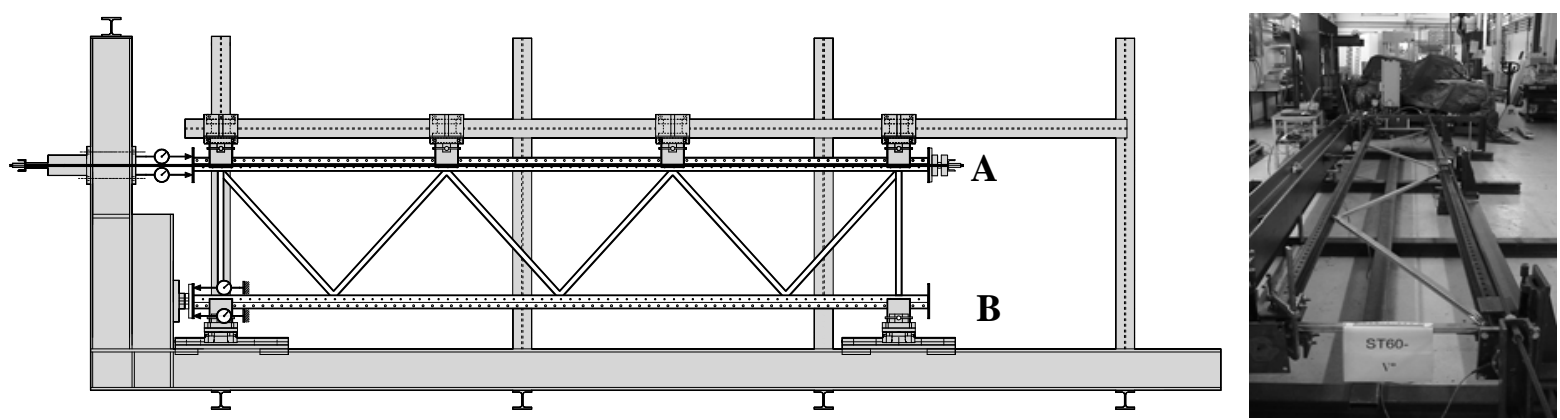

Figure 4. Tests Set-up for Shear Test on Upright Frames Designed at the University of Trento

The shear stiffness $\mathrm{S}_{\mathrm{D}}$ may be employed to determine a reduced bracing area or to characterise an equivalent spring for the bracing connections.

The authors carried out an experimental campaign which comprised approximately 100 tests on 23 different typologies of upright frames. The specimens, consisting of 3 complete panels, involved different upright dimensions, bracings systems and panel geometries. The ratio between the width and the length of the panel (aspect ratio) ranged between 0,33 and 0,85. In all specimens, the connections between the uprights and the bracing system were bolted. The load was increased up to collapse, in order to obtain information on the overall behaviour of the frame in the full range of its response. This information might be important for modelling the rack system.

Particular care was taken with the design of the test rig. One upright (upright B in Figure 4), is hinged at its ends, while the other (upright $\mathrm{A}$ in Figure 4), rests on frictionless supports, so as to guarantee the planarity of the frame. The tests were carried out for the two configurations shown in figure 5 . Four tests were carried out for each type of upright frame: three with configuration 1 and one with configuration 2.

\section{Test configuration 1}

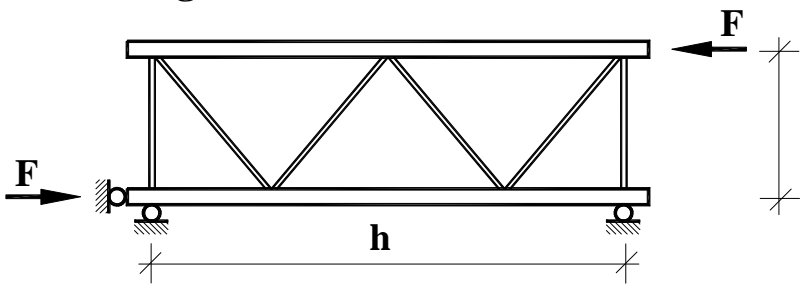

Test configuration 2

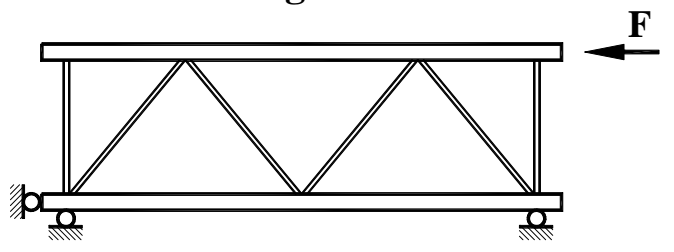

Figure 5. Test's Configuration

The experiments also allowed for a check of the applicability of the European testing procedure. Moreover, they enabled understanding the effectiveness of the bracing system in both configurations and the influence of the connections between the upright and the bracing members. 
The results showed that:

- the test configuration affects in a negligible way the load-displacement curve in the load range addressed by the European Standard $(0-6 \mathrm{kN})$ [3]. As shown in Figure 6, more pronounced differences were observed as the load increased due to the different load resistance mechanisms associated with each configuration. Furthermore, a more favourable mechanism results in a substantial increase of the collapse load (Figure 6 a);

- the connection system between the upright and the bracing members strongly affects the frame performance. Figure 7 compares the test results related to two upright frames differing only in the connection system between the uprights and the bracing members. The noticeable differences in the load-displacement responses can be explained by observing that the connection systems exhibit different local effects. Focusing the attention on a nodal point of the lattice structure, it can be noted that the bracing members are eccentrically connected to the uprights, which results in local torsion. As the distance between the bracing members increases, the local torsion applied to the upright is more pronounced. The global response of the uprights, which have a low torsional stiffness, is greatly influenced by these local effects occurring even for very small loads. Torsion associated with eccentricities of the upright-bracing connections reduces substantially both the stiffness and the strength and, therefore, should be absolutely minimised;

- the torsional deformation of the uprights was observed near collapse in all the specimens, also in the case of bracing systems with small eccentricities (e value in Figure 7). Such a phenomenon is enhanced by the buckling of the compressed diagonal;

- the collapse was caused by the instability of the bracing members (Figure 8a) and involved significant deformations of the connections (Figure 8b). In a few cases the connections failed (Figure 8c).

a)

b)
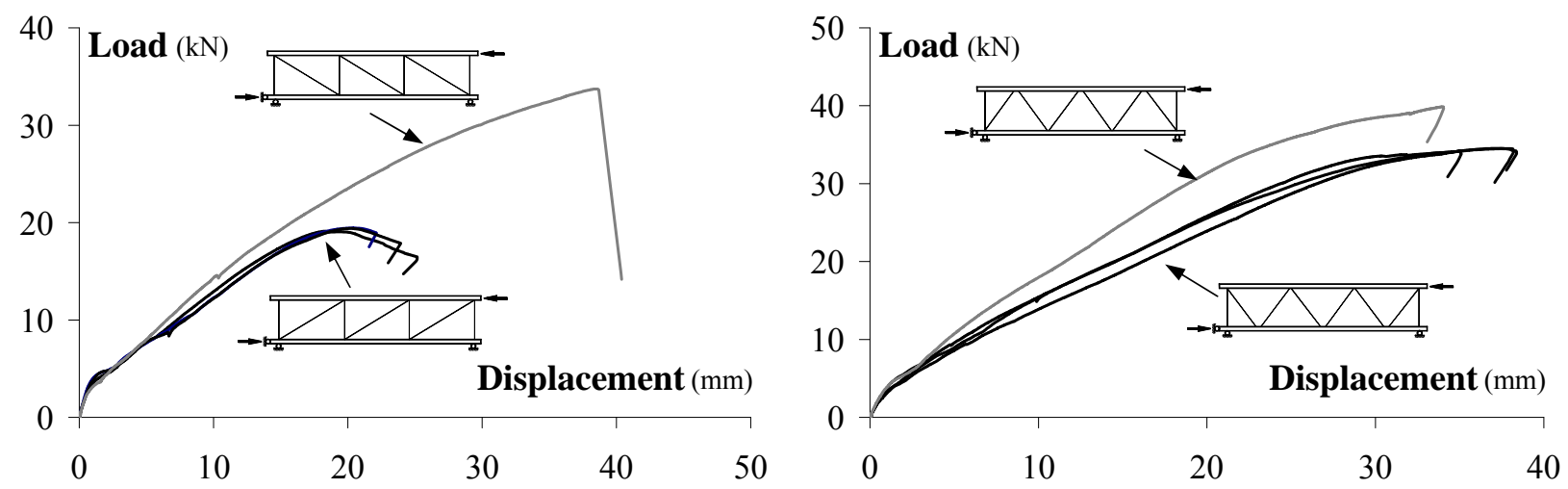

Figure 6. Typical Experimental Load-displacement Curves 


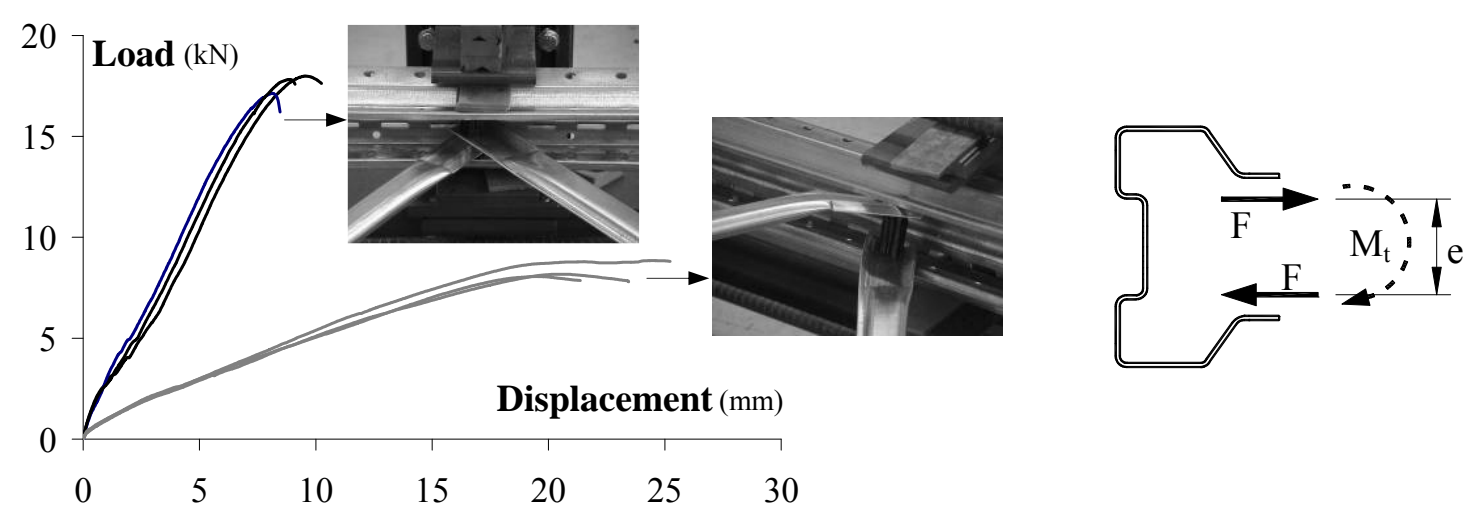

Figure 7. Influence of the Connection System between the Bracings and the Uprights
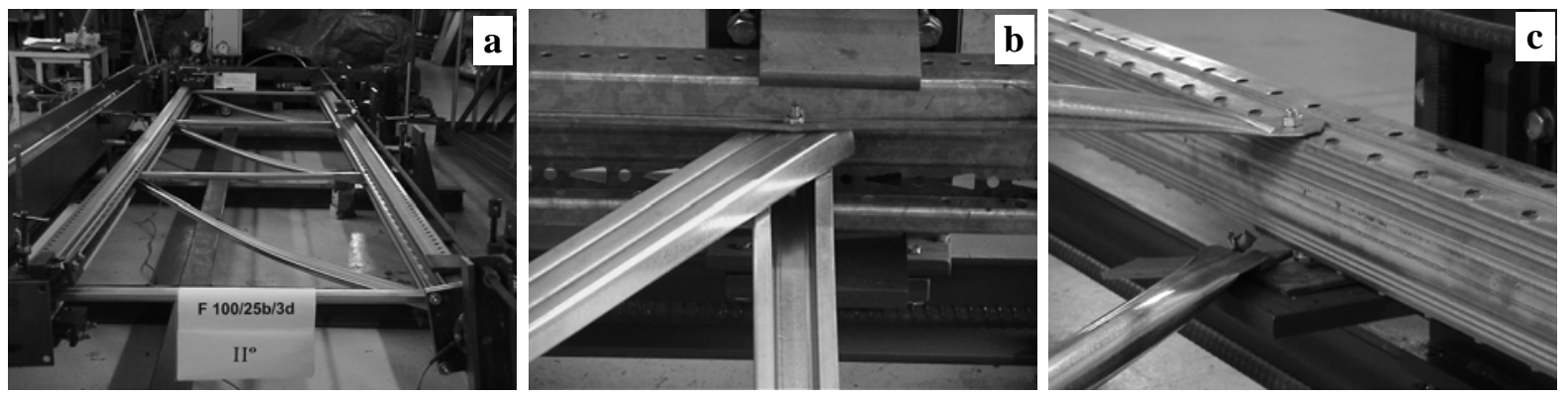

Figure 8. Typical Collapse Modes

The evaluation of the test results in accordance with the European Standard [3] made it possible to point out a few critical aspects of the recommended procedure.

The load-displacement curves (F- $\delta$ curves) are non-linear from the very beginning. This leads to difficulties in applying the procedure of the Standard [3], which requires the determination of a best fit straight line.

The theoretical values of the shear stiffness $\mathrm{S}_{\mathrm{D}}$ are substantially higher than the experimental ones (up to 60 times). The 'uncertainty' on the evaluation of the experimental shear stiffness and the assumptions underlying the theoretical $\mathrm{S}_{\mathrm{D}}$ are the two main causes explaining such an enormous difference.

Similar conclusions were reached in the study carried out by Godley and Beale [24]. The authors analysed the response of upright frames characterised by different upright sizes, numbers of panels and bracing patterns. The study comprised 80 tests on upright frames and numerous FE numerical simulations. The work pointed out that parameters such as the connection eccentricity, the bolt bending or the axial shortening of the uprights must be included in the theoretical analysis to obtain satisfactory agreement between theory and experimental results. If such contributions are considered the scatter between the theoretical and experimental values of $\mathrm{S}_{\mathrm{D}}$ is reduced. Further improvements could be achieved if effects such as the local distortion of the uprights at the connection with the bracings and the bolt looseness are taken into account.

The above considerations clearly indicate the need for testing. The theoretical equations for $\mathrm{S}_{\mathrm{D}}$ should not be used directly. They rather enable the determination of an equivalent value of the bracing area from experimental results. A numerical approach to the problem, whenever possible, is quite complex due to the substantial influence of the local effects on the frame response. The 
reliability of the analysis requires the ability to reproduce the actual frame behaviour and, therefore, leads to complex models, which must, in any case, be validated against the experimental results.

\section{THE JOINTS}

In racks, as in traditional framed structures, joints play a fundamental role in the frame performance. This is clear in the down-aisle direction, since the degree of continuity of the beam-to-column and the base-plate connections is fundamental in providing stability to the system. Therefore, an adequate approximation of the joint behaviour is of vital importance for the analysis and design of rack structures.

Studies carried out by different authors [25,26,27] enabled an overall understanding of the quite complex response exhibited by the joint types usually employed in pallets racks. The presence of lack of fit and the local deformation of both the connected members and the connector lead to moment-rotation relationships that are highly nonlinear even for very small loads. Beside this semi-rigid nature, the joints are 'partial strength joints'. Moreover, the variety of joint components and connection systems is fairly large and in permanent 'evolution', due to the need of innovation typical of a competitive market. As a consequence, the well-known models to estimate the joint performance in traditional steel framed systems [28] cannot be straightforwardly extended to rack joints. Furthermore, the complexity of the various phenomena involved in the joint response (e.g., large plastic deformation, highly localized contact forces, inelastic local buckling...) calls for experimental analysis.

Tests to determine the behaviour of beam-to-column joints appear in all codes for pallet racks [3,4,5]. The European Standard [3] also specifies a test to characterise the response of base-plate connections.

The following two sections focus on joint performance and on its influence on the frame response. From the perspective of design by testing, the code specifications to perform tests and evaluate results are first addressed. The discussion is focused on the main issues of the experimental analysis and the possible 'limits' of the code recommendations. Frame studies carried out by the authors are presented in order to illustrate the sensitivity of the frame response to the joint behaviour and/or modelling.

\subsection{Beam-to-column Joints}

In pallets racks, the connection between the upright and the beam is an easy-to-handle mechanical connection. As already mentioned, the connected profiles and the connection itself may exhibit a wide variety of shapes, dimensions and wall thickness of members, and of shape and dimensions of connecting elements. Nevertheless, some common features can be identified, which are summarised next.

Beams are usually built by welding two thin-walled channels to form a closed section. End connectors are welded at the beam ends, positioned either symmetrically or asymmetrically with respect to the beam axis. The connectors include tangs that accommodate into the holes located on the front wall of the upright, thus creating the connection (Figure 9). This simple connection system allows the rack levels to be adjusted to the storage needs. The geometries of the tangs, beam-end-connector and holes on the upright are designed to facilitate the engaging and to reduce as much as possible the lack of fit and the joint looseness. Moreover, connections are usually provided with locking devices to prevent accidental unlocking or knocking-out of the beam. 

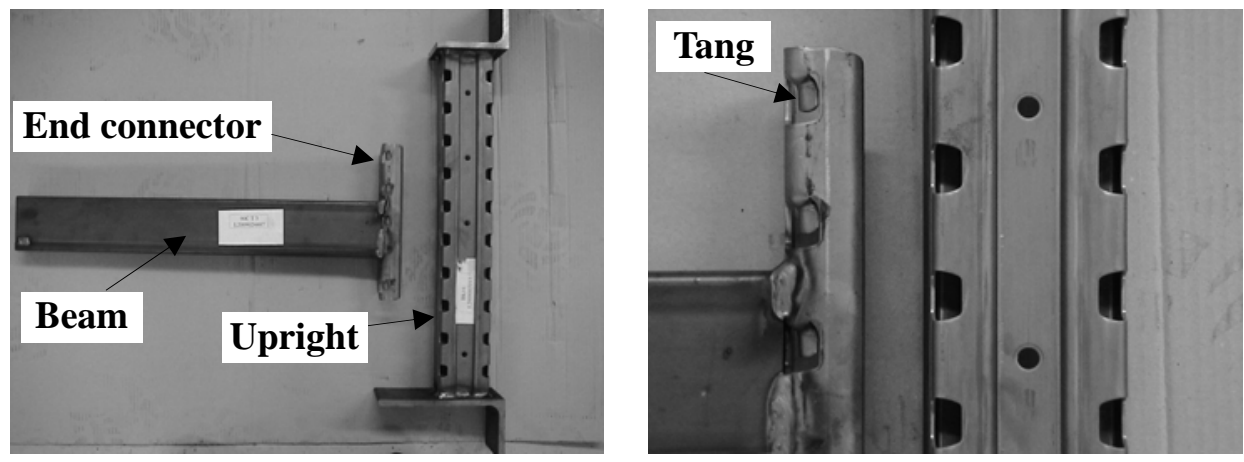

Figure 9. Typical Beam-to-column Connection

When subject to a bending moment, the connectors rotate outwards and tend to tighten up. The moment transferred from the beam to the upright is associated with distortion of the end connectors and local deformation of the upright wall. According to the traditional criterion, these joints would be classified as semi-rigid [28] as pointed out by various authors [25,26,27]. Baldassino and Bernuzzi [26] analysed the results of more than 200 tests on 52 types of beam-to-column connections under bending. Their work showed that the considered connections were characterized by a limited degree of flexural continuity. However, the results of an extensive numerical investigation clearly indicated that such flexible joints have a significant influence on the frame performance. Therefore, it was concluded that when the joint response falls in the flexible domain, the semi-continuous frame model has to be adopted in order to accurately assess the frame response.

This central role in providing the rack lateral stability calls for specific analyses aimed at investigating the joint performance under bending. With this aim, the European and the North American Standards [3,5] provide recommendations for designing, performing and evaluating 'ad hoc' tests to assess the stiffness and moment capacity of the joint. Although the purpose of the tests is the same, the test set-up, procedure and method of evaluating the results are quite different.

The European Standard [3] specifies two types of tests: the bending test and the looseness test. While the former is aimed at assessing the stiffness and the moment resistance, the latter enables the determination of the initial looseness of the joint, an important parameter also for determining the rack frame geometrical imperfection. Both tests adopt the same specimen geometry: a stub of the upright section, connected to a counter frame, and a short length of beam, connected to the central part of the upright (Figure 10). The load is applied at a distance of $400 \mathrm{~mm}$ from the face of the upright. During the tests, the rotation of the end connector is measured (Figure 10). The bending and looseness tests differ in the loading history. In the former, a first cycle of loading and unloading allows for the lack of fit to take place before the load is increased up to the collapse of the specimen. The latter involves a single load cycle up to a moment approximately equal to $\pm 10 \%$ of the joint ultimate moment.
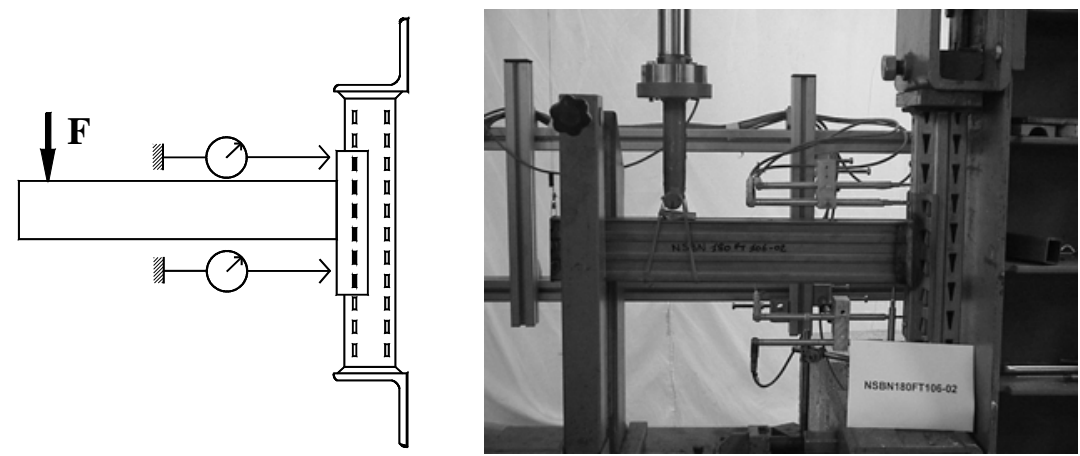

Figure 10. Typical Beam-to-column Connection 
Typical experimental responses from a bending and a looseness test are shown in figures 11a and $11 \mathrm{~b}$, respectively. The European Standard [3] provides detailed methods for evaluating the test data and for defining a design moment-rotation relationship. The amplitude of the initial looseness is obtained by means of a quite simple procedure. The intersection points between the rotation-axis and the lines characterising the 'linear range' of the moment-rotation relation (i.e., points A and B in figure 12) enable the determination of a segment (segment $\mathrm{AB}$ in figure 12), whose length is assumed to be twice the value of the initial looseness $\left(\theta_{1}\right)$.

The moment-rotation law is obtained by means of a time consuming procedure, which also accounts for the deviations of the actual thicknesses and steel yield strength of the joint components, with respect to their nominal values.

Two design models are possible: while one approximates the experimental results by a multi-linear relationship, the other one adopts an elastic-perfectly plastic law. In both cases, it is necessary to determine the design moment resistance $\left(\mathrm{M}_{\mathrm{Rd}}\right)$, computed in accordance with the limit states approach [3]. The experimental moment-rotation curves, as well as the related models, are assumed to be bound by the $\mathrm{M}_{\mathrm{Rd}}$ value.

The multi-linear law is selected by approximating the experimental moment-rotation relationship, while strictly remaining below it (see the dashed line in Figure 13). No practical rules are given.

In the case of a bi-linear moment rotation relationship, the stiffness of the elastic range $\left(\mathrm{k}_{\mathrm{n}, \mathrm{i}}\right)$ is selected as the slope of the secant line passing through the origin and defining approximately equal areas between it and the experimental curve (i.e., areas $A_{1}$ and $A_{2}$ in figure 14). To reduce the deviation between the experimental and numerical results, the stiffness should be selected by considering as additional criterion the condition $\mathrm{k}_{\mathrm{n}, \mathrm{i}} \leq 1,15 \cdot \mathrm{M}_{\mathrm{Rd}} / \theta_{\mathrm{i}}$ (Figure 14). The stiffness to be adopted in design $\left(\mathrm{k}_{\mathrm{m}}\right)$ is the average value of at least three tests.

a)

b)
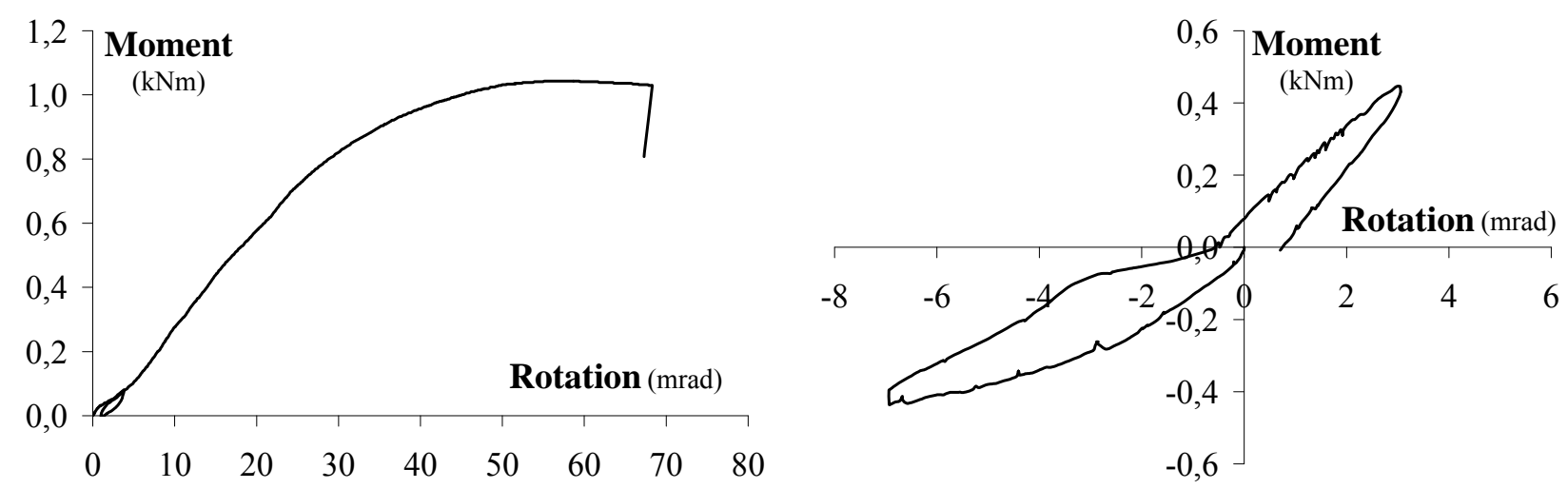

Figure 11. Typical Test Results of a Beam-to-column Connection:

a) Bending Tests and b) Looseness Test 


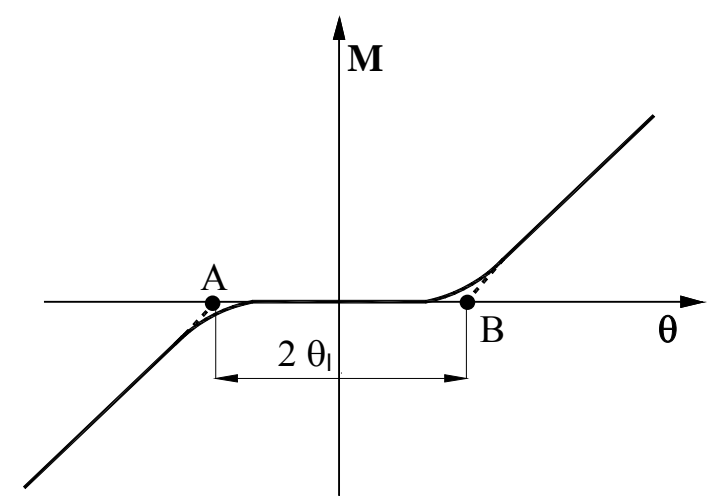

Figure 12. Evaluation of the Initial Looseness
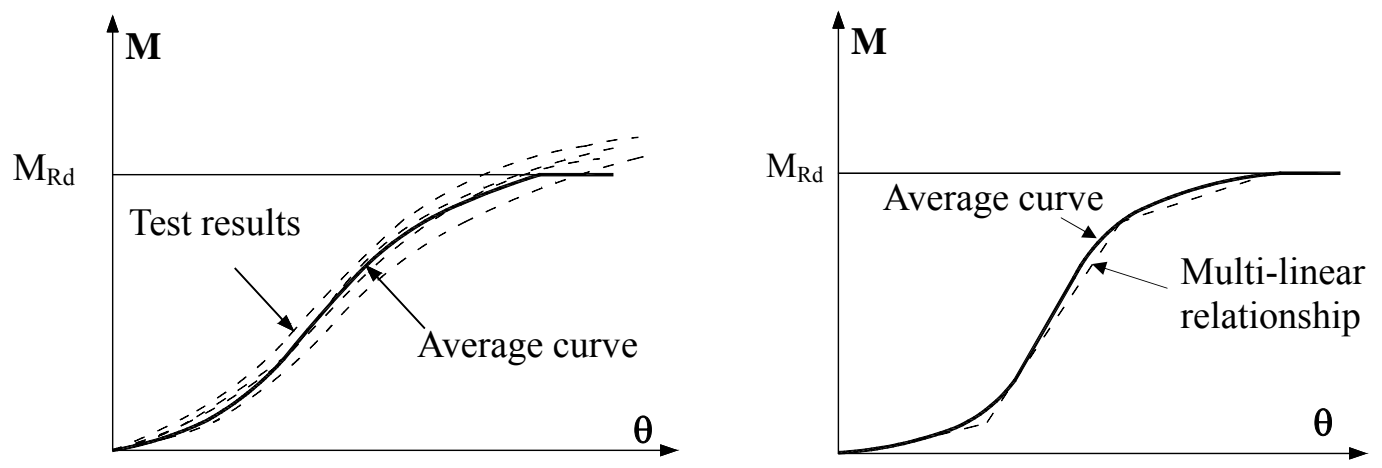

Figure 13. Evaluation of a Multi-linear Moment-rotation Relatonship for Beam-to-column Connection
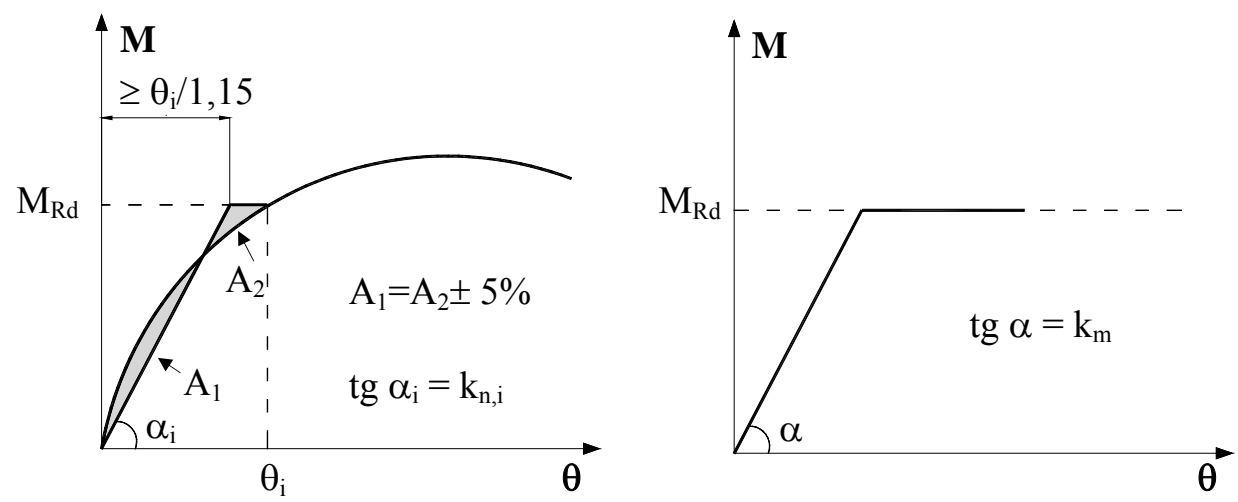

Figure 14. Evaluation of the Initial Stiffeness

The initial looseness and linearised moment-rotation relationship define the beam-to-column joint behaviour in bending. In the frame analysis, the initial joint looseness $\left(\theta_{1}\right)$ is incorporated as an additional sway frame imperfection. A more accurate approach is usually precluded by numerical difficulties. The moment-rotation response is then simulated by means of rotational springs. The European Standard [3] assumes a $\mathrm{M}-\theta$ relationship symmetric for both positive and negative bending moments. It should be mentioned that this assumption is not consistent with the experimental results (Figure 15) [26], nevertheless it is be acceptable for design purposes. Numerical studies carried out on typical rack configurations confirmed the negligible influence of the joint symmetry assumption on the frame performance [26]. 


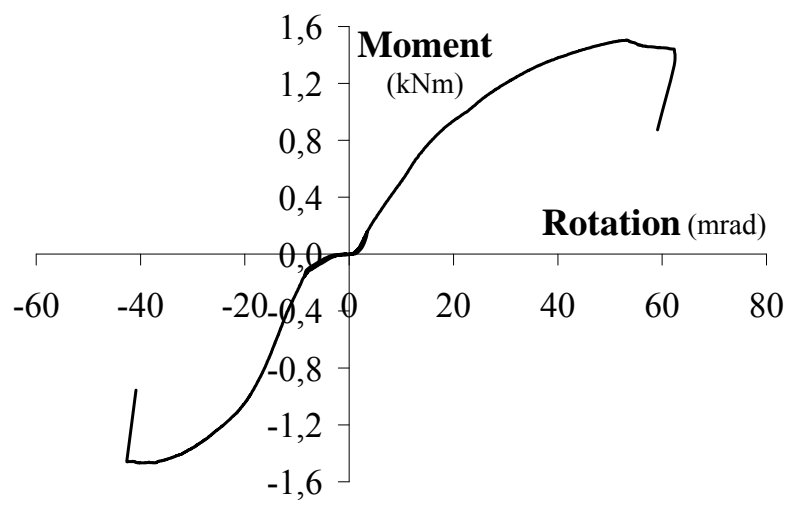

Figure 15. Beam-to-column Joint Response under Positive and Negative Bending Moment

The North American Standard [5] specifies two different tests on beam-to-column joints: the cantilever test and the portal test. The cantilever test, which is similar to the European bending test, is aimed at assessing both the joint stiffness and moment capacity. However, it is mentioned that, in this test, the joint deformability (or stiffness) might be non negligibly affected by the shear force. Therefore, the portal test must be considered in order to provide a more accurate evaluation of the joint stiffness (Figure 16a). The test is carried out on a substructure composed by four uprights, hinged at the base, connected by two beams. The specimen is first subject to the vertical service load, followed by the corresponding design horizontal load, applied at the beam level. The frame sways and the beam-to-column connections rotate in opposite directions, so that the rotation caused by the vertical load increases in one connection and decreases in the other one. The analysis of the portal test results leads to an appraisal of the average value of the joint stiffness, accounting for the joint behaviour asymmetry when the frame sways. However, Harris and Hancock [29] observed that the portal test enables the evaluation of the joint behaviour only for relatively small joint rotations, which does not fully reflect the actual joint response in a sway frame. In particular, they point out that the portal frame results greatly depend on the level of joint bending moment under the vertical loads, due to the non-linear joint behaviour (Figure 16b).

a)

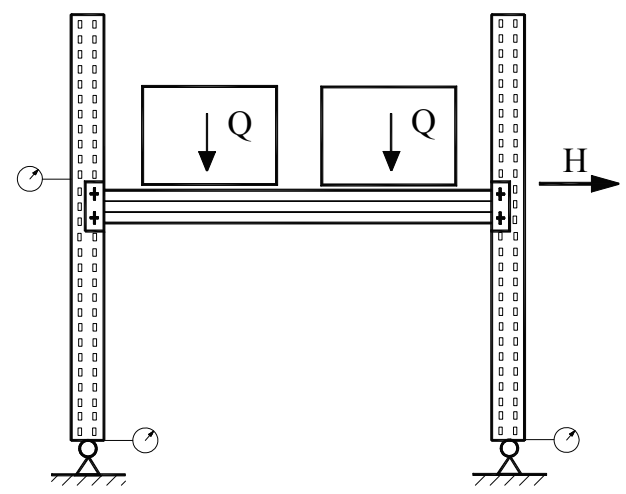

b)

Figure 16. Test Set-up for Portal Test

The remarkable influence of the joint response on the frame performance justifies the great attention paid by the Standards to its characterisation. The authors carried out a numerical study aimed at investigating such an influence [30]. Two rack configurations, involving different numbers of bays and levels, were selected within a typical practical range. The attention was focussed on the rack behaviour in the down-aisle direction. For both frame configurations, the same profiles (uprights and beams) and connections (base-plate and beam-to-column) were considered. All the joints were experimentally characterised in accordance with the European Standard [3]. The 
analyses were performed with the PEP program [31], which enables the incorporation of material and geometrical non-linearity, semi-continuity and the influence of the axial load on the response of the base joints. A simplified bi-linear relationship was assumed for the end connectors. The influence of the beam-to-column joints on the frame performance was studied by selecting 3 joint stiffness values: $2 \mathrm{k}, \mathrm{k}, 0,5 \mathrm{k}$, where $\mathrm{k}$ is the experimental joint stiffness. In addition, initial frame out-plumb angles of 1/1000,1/200 and 1/100 were considered to simulate a wide range of joint looseness amplitudes. Three models were adopted for the base joint: hinge, fixed base and semi-rigid. For the last one a simplified bi-linear curve was assumed. A total of 54 cases were analysed.

The results of this study showed that:

- an increase of the beam-to-column joint stiffness may not lead to an increase of the load capacity. This is mainly due to the change of the collapse mode, which may be associated with the reaching of the maximum rotation capacity of the joint;

influence of the initial out-of-plumb: the increase of the beam-to-column looseness leads to a decrease of the load capacity, for realistic out-of-plumb angles. However, the results do not show any clear relation between the out-of-plumb and the ultimate load;

- the single parameter affecting the frame performance the most appears to be the base restraint.

The above results point out the importance of the joint rotation capacity. No attention is given in the Standard [3] to this parameter and such a gap needs to be filled. Indeed, the accuracy required in the looseness tests seems to be insufficient, and a more accurate assessment of the end connector stiffness is required. However, the results also seem to confirm that a more refined moment-rotation law (i.e., the multi-linear model) does not lead to a real increase of the accuracy of the frame analysis.

As pointed out in this section, the experimental procedures appear fairly demanding on both the test performance and the evaluation of the test results. Moreover, even a small variation of the joint configuration calls for a new series of tests. The numerical analysis based on the FE method [14] seems to be a viable alternative, which would also allow for a deeper understanding of the importance of the various factors involved. In recent years, some attempts were made along this direction. The results obtained showed a general good agreement between the experimental and numerical analyses, but also made it clear that the reliability of the numerical models strongly depends on their calibration against experimental results. In addition, a labour-intensive and time-consuming data input (including the FE mesh) is always required in order to adequately capture the local phenomena, that affect the joint performance and trigger the frame collapse [32]. A convenient alternative is the so-called 'component method' [28], which builds up the joint response on the basis of the behaviour of its components. Recently, Kozłowski and Ślęczka [33] presented a preliminary research study of the application of the component method to rack joints. This work involves five joint typologies, identifies the key joint components and proposes equations to evaluate their stiffness and flexural resistance. Although the results are encouraging, an in-depth study aimed at further validating the model for a wider range of joint typologies remains a necessary pre-requisite for any possible use in design practice.

\subsubsection{Base-plate connection}

Base joints of rack frames are peculiar due to the configuration and components adopted. Therefore, their response is different from that of base joints in traditional steel frames. If reference is made to the Italian practice, base joints are typically built up from 'ad hoc' designed base-plate elements bolted to the uprights and connected to the floor by means of fixing systems (chemical plugs, 
bolts...). Lack of fit between the base-plate element and the upright, local plastic deformations of the upright at the connection to the base-plate element, local buckling of the upright, the interactions between the aforementioned phenomena and the base plate deformation are the main factors influencing the stiffness, resistance and ductility of the joint.

In order to account for the base joints response in the analysis, different approaches are prescribed by the European and the North American Standards [3,5]. The European Standard [3] provides two possible approaches: either to neglect any rotational restraint (i.e., model the joint as a hinge) or to perform 'ad hoc' tests. In the latter case, to account for the influence of the axial load on the joint response, it is recommended that tests are performed for at least two different axial load levels, selected in the range up to the maximum design load for the upright.

The North American Standard [5] adopts a simplified approach: the base joint is modelled by a linear moment-rotation (M- $\theta$ ) relationship. The joint stiffness is determined by considering only the elastic deformation of the concrete floor and does not depend on the axial load. The rotational stiffness of the joint depends only on the dimensions of the upright. Such a difference between the North American and the European Standards [5,3] can be explained by the different base joint typologies employed.

In recent years, the authors carried out an experimental study of base-plate joints of Italian rack frames [34]. The campaign comprised 200 tests on 25 different types of commercial connections, performed in accordance with the European Standard [3]. The specimens consisted of two stub-columns symmetrically connected to a concrete cube by the fixings adopted in the actual structure (Figure 17).
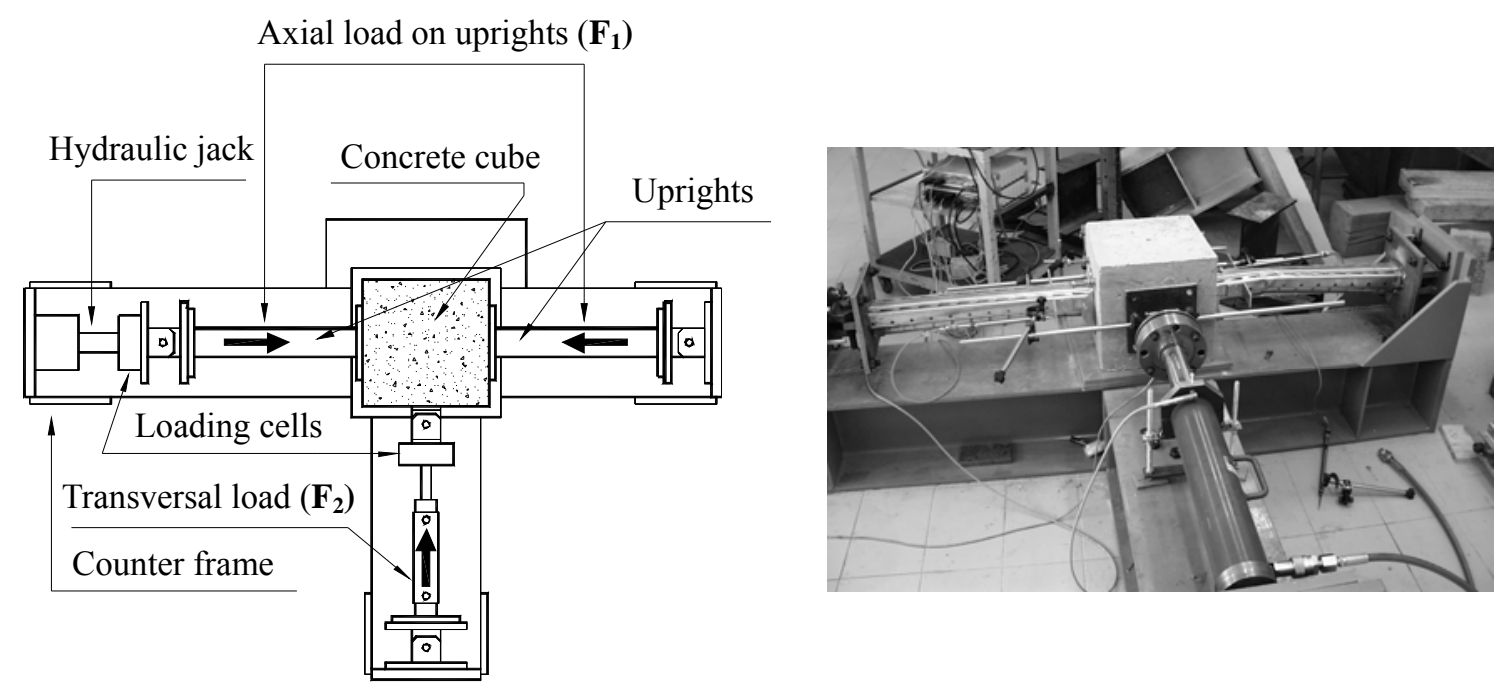

Figure 17. Test set-up for Tests on Base-plate Connections

The concrete cube simulating the floor surface is free to move horizontally in the direction of the applied lateral force and restrained from rotating about the vertical axis. Two hydraulic jacks apply the loads to the specimen: while the first one imposes the specified axial load $\mathrm{F}_{1}$ on the upright, the second one applies a transverse load $F_{2}$ to the centre of the cube. During the test, the rotation of the column bases, with respect to the concrete cube, and the horizontal displacement of the cube are measured.

The test results showed a non-negligible sensitivity to some features of the testing rig. Indications on how to improve the test apparatus were obtained and summarised next: 
- the joint response is highly sensitive to small variations of the axial load $F_{1}$ occurring during the test, stemming from the modified system configuration due to force $F_{2}$. Therefore, it is important to have a reliable load control system to keep the axial load $\mathrm{F}_{1}$ constant;

a vertical displacement of the concrete cube can occur, due to the unavoidable geometrical imperfections of the base connections and/or eccentricities of forces $F_{1}$ and $F_{2}$ with respect to the centre of this element. This effect requires an efficient vertical restraint.

Furthermore, the concrete cube tends to rotate near the collapse, thus inducing a parasitic bending contribution triggering the premature collapse of the base joint. The magnitude of this perturbation cannot be determined.

Typical moment-rotation relationships are presented in figure $18 \mathrm{a}$. The rotation is evaluated as the average value of the relative rotations between the cube and the base joint, measured on the right and left hand sides of the concrete cube. The moment applied to the column base is calculated by considering both the first-order contribution of the transversal load $F_{2}$ and the second-order effect of the axial load $\mathrm{F}_{1}$, due to the lateral displacement of the concrete cube.

a)
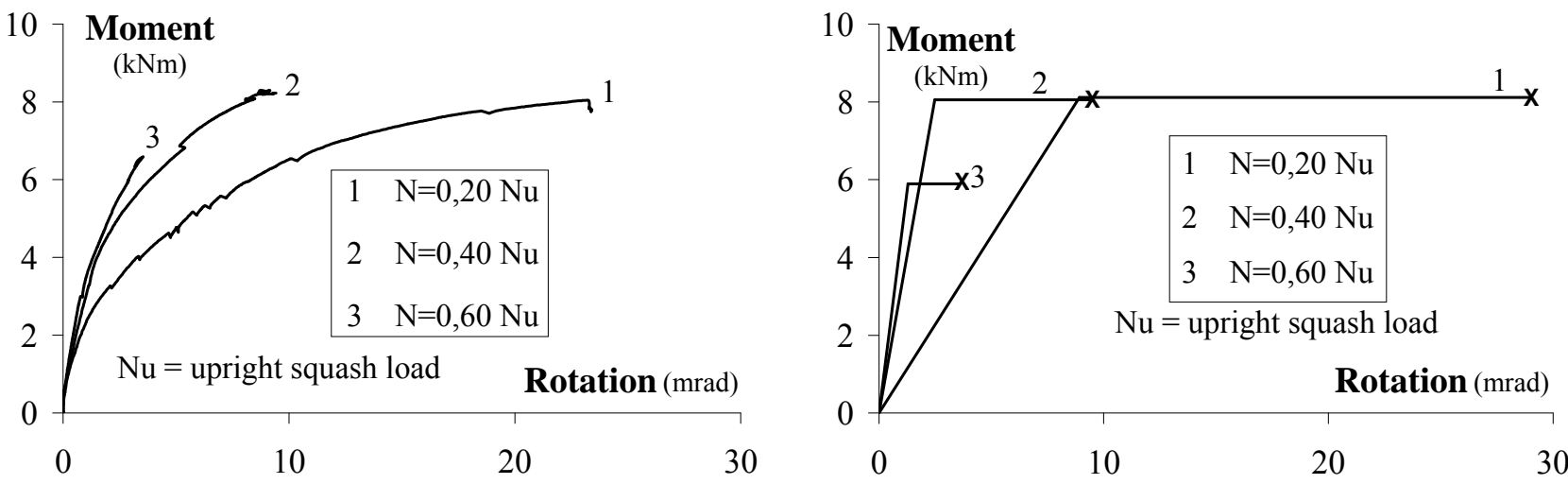

Figure 18. Typical Moment Rotation Relationship for Base-plate Connections:

a) Experimental Results and b) Simplified Relationships

Due to the large variability of the typologies tested and the range of axial load applied to the specimens, it is not possible a direct comparison between the tests results. However, a few general comments on the experimental results can be made:

- the influence of the axial load on both the stiffness and the ultimate moment is substantial. This confirms the need to perform tests for an adequate number of axial load values within the range of use of the upright;

- collapses were caused by plasticity and instability of the upright near to the base-plate. Remarkable deformations of the fixing system to the concrete never occurred;

- the interaction between the base-plate element and the upright could significantly affect the whole joint response. In particular, the local restraint offered by this element to the upright deformation influences both the collapse mode and the joint stiffness [34].

For design purposes, test results should be 'transformed' into simplified moment-rotation relationships accounting for the influence of the axial load on the base joint performance. The European Standard [3] specifies a procedure to evaluate the tests results: for each axial load level, the experimental curves are handled following the procedure prescribed for beam-to-column joints, and an elastic-perfectly plastic moment-rotation relationship is obtained. Typical results of such analyses are presented in figure $18 \mathrm{~b}$. 
A crucial question for design purposes concerns the way in which such simplified relationships should be considered in numerical simulations. In principle, a domain $\mathrm{M}-\mathrm{N}-\phi$ should be defined, with associated rules enabling the determination of the elastic stiffness. In order to simplify the joint model, and in the absence of adequate knowledge, the European code [3] specifies a linear interpolation between the ultimate moment and the joint stiffness for different axial load levels. No rules are given for determining the rotation capacity.

As mentioned before, the North American Standard [5] adopts a very simple theoretical model for the base joint, which relates the elastic stiffness to the joint geometry and the concrete elastic modulus. Recently Sarawit and Peköz [35] carried out an extensive numerical study of base joints for different upright sections, relative positions upright-base plate, and base plate thickness. The study made it possible to improve the equation proposed in the Standard.

From the design point of view, the adoption of a base joint model, even in the simple form specified by the European Standard [3], leads to a more reliable evaluation of the frame performance, but also it significantly increases the computational effort and, requires codes able to incorporate M-N-k- $\theta$ relationships to model the joint. Such a complexity can only be justified if the base joint strongly affects the frame performance.

In order to investigate this issue, the authors recently carried out a numerical study of rack systems with very flexible beam-to-column joints $[34,36]$. The influence of the base restraint, as well as of the way the base joint response is incorporated into the down-aisle frame model, were investigated using the program PEP micro [31]. Each frame configuration combined different base connections and beam-to-column joints. Each joint type was experimentally characterised in accordance with the European Standard [3]. The program linearly interpolates the base joint M- $\theta$ curves associated with different axial load level and the analyses incorporated values of the out-of-plumb angle $\phi$ ranging from 0,001 to $0,01 \mathrm{rad}$. The beam-to-column joints were modelled as semi-rigid and a wide range of stiffness was considered (starting from the experimental value). Four restraint conditions at the base were investigated: hinge, fixed and two semi-continuous joints. The last ones differ in the location of the rotational springs: one model concentrates all the joint deformation at the base, while the other separates the contributions of the end-plate and the upright, locating them in the appropriate positions.

The results of the study showed that:

- the frame response is strongly influenced by the base restraint condition, regardless of the stiffness of the beam-to-column joint. If the load multiplier is considered, the assumption of a fixed base, leads to an increase of the load multiplier by up to $209 \%$, with respect to the hinged base;

- the sway imperfection has a non-negligible influence on the frame response: this parameter becomes less important when the end connector flexibility increases;

the assumption of an hinged base, prescribed by the European Standard [3] in the absence of tests results, is fairly penalising: the load multiplier for the actual base restraint is, on average, $103 \%$ larger than the hinged base one;

- the influence of the variation of the beam-to-column joint stiffness increases with the base joint stiffness. As a consequence, it is not worth improving the beam-to-column joint performance when the base joints are very flexible;

- the frame response determined by considering the semi-rigid base joint behaviour appears not to be sensitive to the way in which the joint flexibility is incorporated into the model.

The above results clearly indicate the need of an experimental characterisation of the base joint. A key parameter for the complete characterisation of the base joint is its maximum rotation capacity. 
Like for beam-to-column joints, no specific requirements are given by the Standard [3] for base joints.

The FE numerical analysis is a useful tool to reduce the cost of experimental studies. Researches carried out in the recent past [36,37], show the potential of this technique in predicting both the joint overall response and collapse mode, even if the complex behaviour of the base joints leads to vey complex numerical models. The need to reproduce the upright boundary conditions and the local phenomena, due to the interaction between the base plate, upright and floor, requires numerical simulations, involving very refined meshes and elements able to model contacts, which should be accurately calibrated against the experimental results. This means that the role of tests remains very important, since they cannot be fully replaced by FE numerical simulations.

\section{CONCLUDING REMARKS}

This paper provides a general overview of the 'design by testing' of steel storage pallet racks. The experimental approach provided by the main standards, namely the European and the North American Standards was presented and discussed. Attention was focused on the key rack components: the upright under compression, the upright frame under shear, the beam-to-column joints in bending and the base joints under compression and bending.

The following issues deserve to be specially mentioned:

- uprights: the experimental procedure proposed by the European Standard appears to be fairly complex. A critical aspect for member testing is the selection of the point of load application. The variable geometry of the cross section along the member length does not allow a definition of a 'centroidal axis of the profile'. Clear guidance on this issue is missing;

- upright frames: the theoretical evaluation of the shear stiffness substantially overestimates the experimental value. Key factors, such as eccentricities of bracing members, bending deformation of the bolts or lack of fits, are not taken into account by the theoretical method. Either experimental values or values yielded by 'realistic' numerical analysis need to be used in design;

beam-to-column joints: since this play a fundamental role in the stability of rack frames in the down-aisle direction, an adequate characterisation is required. Nevertheless, the results of frame analyses seem to indicate that a refined moment-rotation law does not lead to a real increase in accuracy. Bi-linear joint models are satisfactory. Although the approach proposed by the European code is fairly demanding, it pays no attention to the joint rotation capacity, even if extensive numerical studies carried out by the authors showed the importance of this parameter;

- base-plate connections: the experimental characterisation is the most appropriate way to capture the behavioural complexity of these joints, as specified by the European Standard. Code recommendations should be improved to include a more complete characterisation of the joint response, namely the influence of the axial load and the maximum rotation.

Design by testing is a demanding procedure due to both the number and complexity of tests required. At present, numerical tools do not seem to be a fully viable alternative: tests are always required to validate numerical models. However, a reduction of the experimental effort may be foreseen as a consequence of the continuous and fast advances in both software and hardware capabilities. 
Industrial rack design would greatly benefit from a deeper knowledge of several issues that need further investigation. For instance, the influence of the perforations on the upright response, the definition of 'realistic' numerical models for upright frames, the application of the 'component method' to rack beam-to-column and base joints, the criteria to estimate the base joint response accounting for bending, axial force, stiffness and rotation capacity.

\section{REFERENCES}

[1] Ghersi, A., Landolfo, R. and Mazzolani, F.M., "Design of Metallic Cold-formed Thin-walled Members", Spon Press, London and New York, 2002, pp. 164.

[2] Hancock, G.J., "Design of Cold-formed Steel Structures", Australian Institute of Steel Construction, 2nd Edition, 1994, pp. 240.

[3] CEN, "EN 15512, Steel Static Storage Systems - Adjustable Pallet Racking Systems Principles for Structural Design", CEN European Committee for Standardization, 2009, pp. 137.

[4] AS, "AS 4084 - Steel Storage Racking", AS Standards Australia, 1993, pp. 41.

[5] RMI, "MH 16.1- Specification for the Design, Testing and Utilization of Industrial Steel Storage Racks", RMI - Rack Manufactures Institute, 2008, pp. 59.

[6] Timoshenko, S.P. and Gere J.M., "Theory of Elastic Stability", 2nd Edition, McGraw-Hill Book Company, New York, 1961, pp. 541.

[7] Hancock, G.J., "Ligth Gauge Construction", Progress in Structural Engineering and Materials, 1997, Vol. 1, No. 1, pp. 25-30.

[8] Trahair, N.S., "Flexural-torsional Buckling", E \& FN Spon, London, UK, 1993, pp. 420.

[9] Gioncu, V., "General Theory of Coupled Instabilities", Thin-Walled Structures, 1994, Vol. 19, No. 2-4, pp. 81-128.

[10] Pekoz, T., "Development of a Unified approach to the Design of Cold-formed Steel Members", American Iron and Steel Institute, Research Report, CF87, No. 1, 1987.

[11] Weng, C.C. and Peköz, T., "Residual Stresses in Cold-formed Steel Members", Journal of Structural Engineering, ASCE, 1990, Vol. 116, No. 6, pp. 1611-1625.

[12] Moen, C.D., Takeru Igusa and Schafer, B.W., "Prediction of Residual Stresses and Strains in Cold-formed Steel Members", Thin-Walled Structures, 2008, Vol. 46, No. 11, pp. 1274-1289.

[13] LaBoube, R.A., Yu, W.W., Langan, J.E. and Shan, M.Y., "Cold-formed Steel Webs with Openings: Summary Report", Thin-Walled Structures, 1997, Vol. 27, No. 1, pp. 79-84.

[14] Zienkiewicz, O.C., "The Finite Element Method", 3rd Edition, McGraw-Hill Company, London, UK, 1977, pp. 787.

[15] Cheung, Y.K., "Finite Strip Method in Structural Analysis", Pergamon Press, Oxford, New York, 1976, pp. 232.

[16] Schardt, R., "The Generalised Beam Theory, Instability and Plastic Collapse of Steel Structures", Proceedings of the M.R. Horne Conference, University of Manchester, Granada, London, 1983, pp. 469-475.

[17] Davies, J.M. and Leach, P., "First-order Generalised Beam Theory", Journal of Constructional Steel Research, 1994, Vol. 31, No. 2-3, pp. 187-220.

[18] Davies, J.M., Leach, P., and Heinz, D., "Second-order Generalised Beam Theory", Journal of Constructional Steel Research, 1994, Vol. 31, No. 2-3, pp. 221-241.

[19] El-Sawy, K.M. and Nazmy, A.S., "Effect of the Aspect Ratio on the Elastic Buckling of Uniaxially Loaded Plates with Eccentric Holes", Thin-Walled Structures, 2001, Vol. 39, No. 12, pp. 983-998.

[20] Moen, C.D. and Schafer, B.W., "Experiments on Cold-formed Steel Columns with Holes", Thin-Walled Structures, 2008, Vol. 46, No. 10, pp. 1164-1182. 
[21] Moen, C.D. and Schafer, B.W., "Elastic Buckling of Thin Plates with Holes in Compression or Bending", Thin-Walled Structures, 2009, Vol. 47, No. 12, pp. 1597-1607.

[22] Eccher, G., Rasmussen, K. and Zandonini R., "Elastic Buckling Analysis of Perforated Thin-walled Structures by the Isoparametric Spline Finite Strip Method", Thin-Walled Structures, 2008, Vol. 46, No. 2, pp. 165-191.

[23] Baldassino, N. and Hancock, G.J., "Distortional Buckling of Cold-formed Steel Storage Rack Sections including Perforations", Proceedings of the Fourth International Conference on Steel and Aluminium Structures (ICSAS '99), Elsevier, Espoo, Finland, 20-23 June 1999, pp. 131-138.

[24] Sajja, S.R., Beale, R.G. and Godley, M.H.R., "Shear Stiffness of Pallet Rack Upright Frames", Journal of Constructional Steel Research, 2008, Vol. 64, No. 7-8, pp. 867-874.

[25] Markazi, F.D., Beale, R.G. and Godley, M.H.R., "Experimental Analysis of Semi-rigid Boltless Connectors", Thin-Walled Structures, 1997, Vol. 28, No. 1, pp. 57-87.

[26] Baldassino, N. and Bernuzzi, C., "Analysis and Behaviour of Steel Storage Pallet Racks", Thin-Walled Structures, 2000, Vol. 37, No. 4, pp. 277-304.

[27] Baldassino, N. and Zandonini, R., "Performance of Base-plate Connections of Steel Storage Pallet Racks", Proceedings of the International Colloquium dedicated to the 70th Anniversary of Professor Victor Gioncu, May 7-8 2004, Timisoara, Romania, pp. 11-20.

[28] CEN, "Eurocode 3 - Design of Steel Structures - Part 1-8: Design of Joints", CEN European Committee for Standardization, 2005, pp. 133.

[29] Harris, E. and Hancock, G., "Stability Testing of Sub-assemblages of High Rise Steel Storage Racks", Proceedings of the International Conference on Advances in Structures (ASSCCA '03), Sidney, Australia, 22-25 June 2003, Vol. 1, pp. 251-256.

[30] Giovannini, M., "On the Response of Industrial Racks" (in Italian), Master Thesis, University of Trento, 2008, pp. 137.

[31] Galea Y. and Bureau A., "PEP Micro - Manuel d'Utilisation", Centre Tecnique Industriel de la Construction Métallique (CTiCM), France, 1998.

[32] Bajoria, K.M. and Talikoti, R.S., "Determination of Flexibility of Beam-to-column Connectors used in Thin Walled Cold-formed Steel Pallet Racking Systems ", Thin-Walled Structures, 2006, Vol. 44, No. 3, pp. 372-380.

[33] Kozłowski, A. and Ślęczka, L., "Preliminary Component Method Model of Storage Rack Joint", Proceedings of Connections in Steel Structures V, Amsterdam, June 3-4 2004, pp. 253-262.

[34] Baldassino, N. and Zandonini, R., "Performance of Base-plate Connections of Steel Storage Pallet Racks", Proceedings of Fifth International Conference on Coupled Instabilities in Metal Structures (CIMS2008), Gregory J. Hancock Symposium, Sydney, Australia, 23-25 June, 2008, pp. 119-130.

[35] Sarawit, A.T. and Peköz, T., "Cold-formed Steel Frame and Beam-column Design", Report of a Research Project AISI-RMI, Report 03-03, 2003, pp. 330.

[36] Scandola, A., "Analysis of Industrial Racks" (in Italian), Master Thesis, University of Trento, 2007, pp. 129.

[37] del Coz Díaz, J.J., García Nieto, P.J., Betegón Biempica, C. and Fernández Rougeot, G., "Non-linear Analysis of Unbolted Base Plates by FEM and Experimental Validation", Thin-Walled Structures, 2006, Vol. 44, No. 5, pp. 529-541. 